NASA/TM-2004-213215

\title{
Ion Engine Grid Gap Measurements
}

George C. Soulas

Glenn Research Center, Cleveland, Ohio

Michael M. Frandina

QSS Group, Inc., Cleveland, Ohio 
Since its founding, NASA has been dedicated to the advancement of aeronautics and space science. The NASA Scientific and Technical Information (STI) Program Office plays a key part in helping NASA maintain this important role.

The NASA STI Program Office is operated by Langley Research Center, the Lead Center for NASA's scientific and technical information. The NASA STI Program Office provides access to the NASA STI Database, the largest collection of aeronautical and space science STI in the world. The Program Office is also NASA's institutional mechanism for disseminating the results of its research and development activities. These results are published by NASA in the NASA STI Report Series, which includes the following report types:

- $\quad$ TECHNICAL PUBLICATION. Reports of completed research or a major significant phase of research that present the results of NASA programs and include extensive data or theoretical analysis. Includes compilations of significant scientific and technical data and information deemed to be of continuing reference value. NASA's counterpart of peerreviewed formal professional papers but has less stringent limitations on manuscript length and extent of graphic presentations.

- TECHNICAL MEMORANDUM. Scientific and technical findings that are preliminary or of specialized interest, e.g., quick release reports, working papers, and bibliographies that contain minimal annotation. Does not contain extensive analysis.

- CONTRACTOR REPORT. Scientific and technical findings by NASA-sponsored contractors and grantees.
- CONFERENCE PUBLICATION. Collected papers from scientific and technical conferences, symposia, seminars, or other meetings sponsored or cosponsored by NASA.

- SPECIAL PUBLICATION. Scientific, technical, or historical information from NASA programs, projects, and missions, often concerned with subjects having substantial public interest.

- TECHNICAL TRANSLATION. Englishlanguage translations of foreign scientific and technical material pertinent to NASA's mission.

Specialized services that complement the STI Program Office's diverse offerings include creating custom thesauri, building customized databases, organizing and publishing research results ... even providing videos.

For more information about the NASA STI Program Office, see the following:

- Access the NASA STI Program Home Page at http://www.sti.nasa.gov

- E-mail your question via the Internet to help@sti.nasa.gov

- Fax your question to the NASA Access Help Desk at 301-621-0134

- Telephone the NASA Access Help Desk at 301-621-0390

- Write to:

NASA Access Help Desk

NASA Center for AeroSpace Information 7121 Standard Drive

Hanover, MD 21076 
NASA/TM-2004-213215

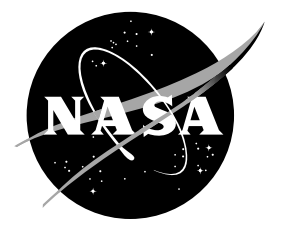

\section{Ion Engine Grid Gap Measurements}

George C. Soulas

Glenn Research Center, Cleveland, Ohio

Michael M. Frandina

QSS Group, Inc., Cleveland, Ohio

Prepared for the

40th Joint Propulsion Conference and Exhibit

cosponsored by the AIAA, ASME, SAE, and ASEE

Fort Lauderdale, Florida, July 11-14, 2004

National Aeronautics and

Space Administration

Glenn Research Center 
This report contains preliminary findings, subject to revision as analysis proceeds.

a

Available from

NASA Center for Aerospace Information 7121 Standard Drive

Hanover, MD 21076
National Technical Information Service 5285 Port Royal Road Springfield, VA 22100

Available electronically at http:/ /gltrs.grc.nasa.gov 


\title{
Ion Engine Grid Gap Measurements
}

\author{
George C. Soulas \\ Glenn Research Center \\ Cleveland, Ohio 44135 \\ Michael M. Frandina \\ QSS Group, Inc. \\ Cleveland, Ohio 44135
}

National Aeronautics and Space Administration

\begin{abstract}
A simple technique for measuring the grid gap of an ion engine's ion optics during startup and steady-state operation was demonstrated with beam extraction. The grid gap at the center of the ion optics assembly was measured with a long distance microscope that was focused onto an alumina pin that protruded through the center accelerator grid aperture and was mechanically attached to the screen grid. This measurement technique was successfully applied to a $30 \mathrm{~cm}$ titanium ion optics assembly mounted onto an NSTAR engineering model ion engine. The grid gap and each grid's movement during startup from room temperature to both full and low power were measured. The grid gaps with and without beam extraction were found to be significantly different. The grid gaps at the ion optics' center were both significantly smaller than the cold grid gap and different at the two power levels examined. To avoid issues associated with a small grid gap during thruster startup with titanium ion optics, a simple method was to operate the thruster initially without beam extraction to heat the ion optics. Another possible method is to apply high voltage to the grids prior to igniting the discharge because power deposition to the grids from the plasma is lower with beam extraction than without. Further testing would be required to confirm this approach.
\end{abstract}

\section{Introduction}

The NSTAR (i.e. NASA Solar Electric Propulsion Technology Applications Readiness Program) ion thruster system on the Deep Space 1 mission has demonstrated the viability of ion propulsion for deep space missions. ${ }^{1}$ Ion propulsion is, therefore, a candidate for several deep space missions, such as Discovery-class missions, and has been selected as the primary propulsion system for the Dawn mission. ${ }^{2}$

A critical ion engine component that affects engine operation, performance, and service life is the acceleration system, or ion optics assembly. The NSTAR ion optics assembly is made up, in part, of two electrodes, labeled the screen and accelerator grids. A critical dimension that directly affects ion optics' performance parameters such as perveance (i.e. the beam current extraction capability) and accelerator voltage, and service life is the gap between the grids. While this grid gap is typically preset during ion optics assembly, the grid gap during engine operation (i.e. hot grid gap) changes due to differential heating and, therefore, thermal expansion of the screen and accelerator grids. This is especially true for grid materials with relatively high thermal expansion coefficients, such as metallic grids. Knowledge of this hot grid gap is essential in properly assessing ion optics' performance parameters and service life.

Titanium ion optics have been investigated for increasing the NSTAR accelerator grid service life capability. ${ }^{3-5}$ Titanium's lower sputter yield is expected to improve NSTAR accelerator grid service life by a factor of about 1.9. However, titanium's $1.8 \times$ higher thermal expansion coefficient than molybdenum caused the grids to make contact during thruster startup, when differential heating of the grids is most severe. ${ }^{4}$ During that test, the thruster was set to $2.3 \mathrm{~kW}$ (i.e. peak NSTAR thruster input power) within 1 minute following discharge ignition, and the screen grid came into contact with the accelerator grid within 5 minutes of ignition near the center of the beam extraction area. 
Mapping this dynamic hot grid gap change during startup would lead to a better understanding of this issue and help to resolve this issue for titanium ion optics.

Hot grid gap measurements have been made in several past studies. Ramsey measured the hot grid gap visually by noting the markings of graduated metal pins that were mechanically attached to screen grid apertures and protruded through accelerator grid apertures. ${ }^{6}$ However, these pins were metallic and at screen grid potential, so beam extraction was not possible because electrons from the neutralizer would be drawn to this high potential conductor. Furthermore, the resolution of these measurements was limited. MacRae, et al. measured the hot grid gap for $30 \mathrm{~cm}$ SEPS ion optics operating over a range of discharge power levels. ${ }^{7}$ This was done by measuring the deflections of metallic pins mechanically attached to both grids near the ion optics center. The screen grid pin protruded through an accelerator aperture. Unfortunately, the reported results were for operation without beam extraction because the screen grid pin was metallic and at screen grid potential, and pin deflections were measured with a large apparatus located immediately downstream of the ion optics. Pollard and Welle measured the hot grid gap for a UK T5 ion engine by imaging the center screen and accelerator apertures at a high angle relative to the surface normal with two long-distance microscopes viewing the apertures at opposite radial locations. ${ }^{8}$ Two measurements were required to account for radial motion. This measurement technique was ideal in that it was nonintrusive and could measure hot gaps with beam extraction. Unfortunately, because radial motion had to be measured to reduce uncertainty, the measurement technique was complex. Furthermore, for ion optics aperture geometries where the accelerator grid aperture is significantly smaller than the screen grid aperture and the grid gap is small, the microscope would have to be placed in beam plume or be retracted with loss of resolution.

Because past hot grid gap measurements provided poor resolution, were restricted to ion engine operation without beam extraction, or were too complex, a new technique was developed for this study. This paper describes a simple technique for measuring the dynamic hot grid gap of an ion engine operating with beam extraction. This measurement technique was successfully applied to $30 \mathrm{~cm}$ titanium ion optics assembly mounted onto an NSTAR engineering model ion engine to help resolve startup issues associated with titanium ion optics. This paper will present and discuss these results.

\section{Test Setup}

\section{A. Hot Grid Gap Measurement Technique}

In this study, the hot grid gap at the center of the ion optics assembly was measured with a long distance microscope coupled to a digital imaging system. The microscope was focused onto an alumina pin that protruded through the center accelerator grid aperture and was mechanically attached to the screen grid. A schematic and photograph of the setup are shown in figs. 1 and 2, respectively. The center of the perforated ion optics was selected for this measurement because this location is where the hot grid gap would be expected to vary the most during heating. The change in hot grid gap was determined by measuring the change in pin height relative to the downstream accelerator grid surface. The use of an insulator material for the pin allowed for ion engine operation with beam extraction. The pin served a second function by acting as a calibration reference for the images. The long distance microscope was located radially to one side of the ion engine and perpendicular to the length of the pin, so that the thruster ion beam did not directly impinge on the microscope. Because the microscope was located within the vacuum facility so close to the ion optics, the measurement resolution could be maximized without placing the microscope within the beam plume.

The alumina pin was cemented onto a small metal fixture that was screwed to the screen grid, shown in fig 3. The screw head had a rectangular shape so that the fixture could be coupled to the screen grid without disassembling the ion optics assembly. Because the screw head protruded into the inter-grid gap, the smallest grid gap possible was estimated to be about $0.28 \mathrm{~mm}$. When installed, the fixture with pin only covered about eight screen grid apertures, or just $0.06 \%$ of the total number of screen apertures. The fixture and pin were also designed to have a small thermal mass to reduce their impact on thermal behavior of the ion optics.

The long distance microscope used for this test had a focal length of $22.5-45.7 \mathrm{~cm}$ with a 16.8-6x magnification. The long distance microscope was modified with vent holes and used a low vapor pressure lubricant so that it would function properly under vacuum. It was also enclosed within a metal casing to protect it from backsputtered material during thruster operation, shown in fig. 2. Because the microscope was inaccessible inside the vacuum chamber, it was mounted to a two axis positioning system to allow for adjustment to compensate for any thruster movement due to heating. A CCD camera attached to the long distance microscope imaged the exposed pin and accelerator grid surface. The camera imaged in black and white and had a $7.95 \mathrm{~mm} \times 6.45 \mathrm{~mm}$ CCD element with $752 \times 582$ pixels, respectively. A sample image is shown in fig. 4 . The camera converted the image to an analog signal and sent it to a computer equipped with imaging software and hardware. These images were digitized, 
displayed, and periodically recorded. Commercially available software was later used to analyze these images to determine movements of the grids and, therefore, the hot grid gap.

Two halogen lamps located about $4 \mathrm{~m}$ downstream and to either side of the beam plume and a low power light bulb near the microscope provided the required lighting. Unfortunately, the lighting also heated the ion optics, which affected the hot grid gap. This effect will be discussed later.

An analysis was conducted to estimate grid gap measurement uncertainty. The analysis included several sources of error, which included microscope misalignment relative to the pin, reference calibration errors, measurement resolution, and pin thermal expansion. The resulting uncertainty was estimated to be within about $0.05 \mathrm{~mm}$ for the measurements presented herein.

\section{B. Ion Optics and Thruster}

The titanium ion optics set utilized for this investigation was that used in refs. 3 and 4. Screen and accelerator grid aperture diameter variations were within $+0 \% /-9 \%$ and $\pm 9 \%$, respectively, of the nominal NSTAR design throughout the active area. ${ }^{9,10}$ The screen grid thickness was also $7 \%$ thicker than the nominal NSTAR design. Although this grid set had bonded together due to temperature differences between the grids during thruster startup on a prior test, the grids were subsequently separated, and aperture alignment and cold grid gap changes were found to be negligible. ${ }^{4}$ For these tests, the cold grid gap at the ion optics center where the pin was mounted was measured to be $0.69 \mathrm{~mm}$. Variations throughout the active area were within $+0 \% /-4 \%$ of this dimension.

The titanium ion optics assembly was mounted onto a NSTAR engineering model ion thruster, labeled EM3 and shown in fig. 2. The mechanical design of this $30 \mathrm{~cm}$ ion thruster is similar to the NSTAR thruster, which is described in detail in refs. 9 to 11. The neutralizer used for these tests was a NEXT laboratory model design, which is described in ref. 12. It will be shown later that the neutralizer had no discernable impact on the hot grid gap.

\section{Power Console, Gas Feed System, and Vacuum Facility}

A power console similar to that described in ref. 13 powered the ion engine. This power console utilized commercially available power supplies that can accommodate ion engine input powers of over $10 \mathrm{~kW}$ with beam power supply voltages of up to $2000 \mathrm{~V}$. A high purity gas feed system was used to provide xenon to the discharge cathode, main plenum, and neutralizer through separate mass flow controllers.

Testing was conducted in Vacuum Facility 11 at NASA GRC. This $2.2 \mathrm{~m}$ diameter $\times 7.9 \mathrm{~m}$ long facility is evacuated with seven cryogenic pumps. The total measured facility pumping speed was greater than $100,000 \mathrm{~L} / \mathrm{s}$ with xenon. The facility base pressure was typically less than $5.3 \times 10^{-5} \mathrm{~Pa}\left(4.0 \times 10^{-7} \mathrm{Torr}\right)$ and background pressures were as high as $5.9 \times 10^{-4} \mathrm{~Pa}\left(4.4 \times 10^{-6}\right.$ Torr $)$ at the peak thruster input power of $2.3 \mathrm{~kW}$.

\section{Test Procedure}

Tests were conducted to determine what effects, if any, that heating from the required lighting and electrostatic pressure from the total voltage between the grids had on the grid gap. During thermal testing from the lighting, the change in grid gap was monitored immediately following application lighting. The engine was unpowered, under vacuum, and was at thermal equilibrium within the vacuum chamber prior to turning on the lighting. After the grid gap had stabilized, the electrostatic pressure test was conducted. During that test, the change in grid gap was monitored while the voltage between the grids was ramped from $0 \mathrm{~V}$ to about $1930 \mathrm{~V}$. The beam power supply output was directly connected to the screen and accelerator grids during this test.

Tests were then conducted to determine the transient and steady-state hot grid gap during thruster operation. The three transient tests included:

1. startup transients at full power;

2. startup transients at low power; and

3. transients due to transitioning from low to high discharge power.

These operating conditions are listed in table 1. During the tests evaluating startup transients, the engine was unpowered, under vacuum, and was at thermal equilibrium within the vacuum chamber prior to thruster startup. The thruster was operated without beam extraction initially, and then with beam extraction to discern differences in between the two operating modes. During operation without beam extraction, the main plenum flow to the discharge chamber was lowered to achieve a discharge voltage similar to that with beam extraction. During the third test, the thruster was operated without beam extraction during the transition from low to high discharge power.

Periodically during these tests, the screen grid ion transparency was measured. This was done by connecting the engine to an electrically floating power supply circuit used to determine the screen grid transparency to discharge chamber ions. The circuit electrically tied the screen grid to the discharge cathode during normal operation, but 
biased the grid negative relative to discharge cathode potential to repel electrons and measure the collected ion current. These data were used to assess screen grid power deposition from discharge ions.

\section{Test Results}

\section{A. Lighting and Electrostatic Effects}

The effects of lighting on the grid gap are shown in fig. 5. As the figure shows, the grid gap increased by about $0.035 \mathrm{~mm}$ within 25 minutes of application of the lighting. Afterwards, the grid gap remained unchanged. This change in grid gap due to lighting represents about $5 \%$ of the cold grid gap. The increase was due to external heating of the accelerator grid, which caused the grid gap to increase. Future tests can significantly reduce this effect by utilizing lighting that is better directed onto the pin rather than the entire thruster, as was done for this test. Regardless, the lighting used for this test will have an impact on the test results reported herein, albeit small.

The effect of electrostatic pressure on the grids (i.e. the force of attraction between the grids from the applied voltage) is shown in fig. 6 . As the figure shows, the grid gap did not change noticeably from electrostatic pressure within the measurement uncertainty of $0.05 \mathrm{~mm}$. This is not surprising. If the grid dome shape and perforation are conservatively ignored, the resulting maximum electrostatic pressure during the aforementioned test was calculated to be about $30 \mathrm{~Pa}$. Accounting for the spherically domed shape of the grids and the reduced elastic modulus caused by the perforation, the screen grid deflection caused by this pressure was calculated to be $5 \times 10^{-4} \mathrm{~mm}$, which is negligibly small. A tangential edge support was conservatively assumed for the deflection calculation. During thruster operation, the hot grid gaps are smaller (to be shown later), and the elastic modulus decreases due to heating. However, the screen grid deflection caused by the electrostatic pressure for a conservatively assumed $0.25 \mathrm{~mm}$ gap, $500^{\circ} \mathrm{C}$ grid temperature, and $1930 \mathrm{~V}$ inter-grid voltage was calculated to be $6 \times 10^{-3} \mathrm{~mm}$, which is still negligibly small. Therefore, electrostatic pressure from the voltages applied on the grids did not contribute significantly to the grid gap changes in the test results that follow.

\section{B. Full and Low Power Startup Transients}

The startup grid gap and grid movement as a function of elapsed time are shown in figs. 7 and 8, respectively, for full power operation and figs. 9 and 10, respectively, for low power operation. During the first half of all plots, there was no beam extraction during thruster operation and the main plenum flow rates were reduced to increase the discharge power to better match discharge power during beam extraction. The main flows were later increased and beam extraction initiated. For the full power case (i.e. figs. 7 and 8) the thruster was turned off after minute 171 and the grid gap monitored as the engine cooled while for the low power case (i.e. figs. 9 and 10), beam extraction was turned off after minute 182 and the discharge was operated as before. The grid movement plotted in figs. 8 and 10, and throughout the remainder of this paper, includes some discharge chamber, thruster mount, and possibly microscope mount movement due to heating of these parts; it is not the movement of the grids relative to the ion optics mounting assembly. Therefore, care must be taken in interpreting these results.

Both sets of plots exhibit very similar behavior during operation without beam extraction. After neutralizer ignition, there was no grid movement. This is not surprising because the neutralizer operates at power levels significantly lower than the discharge chamber and is separate from the remainder of the thruster, so that heat transfer to the grids is inefficient. Immediately following discharge ignition, however, the grids rapidly expanded. In both cases, the screen grid expanded more rapidly than the accelerator grid, likely because it had a significantly lower thermal mass, it was better exposed to the discharge plasma, and power deposition to this grid was larger, which will be shown in a later section. This caused the hot grid gap to reduce quickly. For the full power case in fig. 7, the smallest grid gap was achieved within about $25 \mathrm{~s}$ following discharge ignition while about $110 \mathrm{~s}$ were required for the low power case in fig. 9. For both cases, the data in figs. 7 and 9 indicate that screw holding the pin to the screen grid likely made contact with the accelerator grid and prevented the grid gap from decreasing further. As a result, the minimum grid gap could not be determined.

Within about 3.5 minutes of discharge ignition at full power, the grid gap began to open, while this occurred after about 4.3 minutes at low power. In both cases, the hot grid gap gradually opened until minimum values were reached. For the full and low power cases, the hot grid gap stabilized after about 31 minutes and 63 minutes, respectively, following discharge ignition and during operation without beam extraction. According to figs. 8 and 10 , the grid dome heights were actually decreasing after the minimum hot grid gap was achieved. The reason for this was likely that immediately following discharge ignition, only the perforated portions of both grids exposed to the discharge plasma were being heated efficiently. The unperforated portions of the grids and the mounting assembly were not exposed to the discharge plasma, so heating of these parts occurred very gradually from conduction and 
radiation heat transfer. As the temperature of the outer perimeter components gradually increased, these components expanded radially and reduced the dome heights of the grids.

When the main plenum flow rates were increased and the ion beam extracted, the hot grid gap changed significantly. When the main plenum flows were increased to the nominal flows and prior to beam extraction, the hot grid gap increased even further as shown in figs. 7 and 9. This occurred because the screen grid dome height decreased, as shown in figs. 8 and, in part, 10. This will be examined more closely in the next section. When beam extraction was initiated, the discharge current was fixed and so no attempt was made to maintain the nominal beam power supply currents listed in table 1 . As a result, the full power beam current was $1.83 \mathrm{~A}$ while the low power current was $0.50 \mathrm{~A}$. After the ion beam was extracted, the hot grid gap decreased significantly and over a short duration. At full power, the hot grid gap decreased within about 2.7 minutes to a new steady-state hot grid gap of $0.34 \mathrm{~mm}$ while at low power, the hot grid gap decreased to $0.40 \mathrm{~mm}$ within about 8.7 minutes. These hot grid gap decreases occurred because the screen and accelerator grid dome heights, as shown in figs 8 and 10, decreased dramatically over approximately the same time period, but the accelerator grid dome height decreased more than that of the screen grid.

A significant finding from this investigation was that the hot grid gaps with and without beam extraction are not the same, as was assumed in refs. 6 and 7, but are significantly different. Therefore, beam extraction is required for a proper measurement of the hot grid gap during thruster operation. Another important finding was that the hot grid gaps at the ion optics' center were both significantly smaller than the cold grid gap and different at the two power levels examined. At full power, the hot grid gap at the ion optics' center was about half that of the cold grid gap. This information is important when assessing ion optics performance parameters and service life.

After about 171 minutes of operation at full power, the thruster was powered off. As figs. 7 and 8 show, the hot grid gap increased rapidly, reaching the cold grid gap within $30 \mathrm{~s}$, and then increasing by $0.1 \mathrm{~mm}$ beyond this cold grid gap during cooling because, as shown in fig 8 , the screen grid cooled faster than the accelerator grid. The screen grid likely cooled faster because the accelerator grid has a significantly higher thermal mass than the screen grid. The grid gap eventually reached the cold grid gap about 22 minutes after thruster operation was terminated.

At minute 182 of low power operation of figs. 9 and 10, the high voltage was turned off and the main plenum flow decreased. Within about 8 minutes, the hot grid gap returned to the same hot gap just prior to beam extraction, as expected.

\section{Low-to-Full Power Transients}

The grid gap and grid movement as a function of elapsed time are shown in figs. 11 and 12, respectively, during a transition from low to full power without beam extraction. The behavior exhibited by the ion optics during this transition was very similar to that exhibited during startup. The grids rapidly expanded, as before. The screen grid expanded more rapidly than the accelerator grid, causing the hot grid gap to reduce quickly. The smallest grid gap was achieved within about $35 \mathrm{~s}$ following the transition to full power. The data in fig. 11 indicate that screw holding the pin to the screen grid likely made contact with the accelerator grid and prevented the grid gap from decreasing further. As a result, the minimum grid gap achieved could not be determined. Within about $65 \mathrm{~s}$ of the transition to full power, the grid gap began to open, gradually increasing until a minimum value was reached. The hot grid gap stabilized after about 22 minutes, respectively, following the transition. According to fig.12, the grid dome heights were decreasing after the minimum hot grid gap was achieved

When the main plenum flow was increased at minute 275 , the hot grid gap changed significantly. Specifically, the hot grid gap increased even further as shown in fig. 11. This occurred because the screen grid dome height decreased, as shown in fig. 12. This screen grid dome height decreased due to a lower screen grid temperature, caused by reduced power deposition to the grid from the discharge plasma. This will be discussed in the next section.

\section{Discussions}

\section{A. Screen and Accelerator Grid Power Deposition}

To better understand some of the trends in the measured data, steady-state power deposition to the grids was examined. During steady-state operation, the power deposited to the grids is equal to power rejected from the grids. This power relation for each grid can be expressed as:

$$
\mathrm{P}_{\text {plasma }}+\mathrm{P}_{\text {disch }}^{\text {rad }}+\mathrm{P}_{\text {grid }}^{\text {rad }}+\mathrm{P}_{\text {mount }}^{\text {cond }}=0
$$


where $\mathrm{P}_{\text {plasma }}$ is the power deposited to the grid from the plasma, $\mathrm{P}_{\text {rad }}$ disch is the net heat radiated from the discharge chamber, $\mathrm{P}_{\text {rad }}$ grid is the net heat radiated between the grids, and $\mathrm{P}_{\text {mount }}^{\text {cond }}$ is the net heat conducted to the ion optics mounting assembly. The power deposited to each grid by the plasma is given by:

$$
P_{\text {plasma }}=J_{i} \cdot\left(\frac{5}{2} \cdot \frac{k \cdot T_{i}}{e}+V_{\text {fall }}+U_{i}-\phi\right),
$$

where $\mathrm{J}_{\mathrm{i}}$ is the ion current collected by the grid, $\mathrm{k}$ is the Boltzmann constant, e is the electron charge, $T_{\mathrm{i}}$ is the ion temperature, $V_{\text {fall }}$ is the fall voltage between the plasma and grid, $U_{i}$ is the ionization potential of singly-charged $x e n o n$, and $\varphi$ is the screen grid work function. ${ }^{14}$

Power deposition from the plasma to the grids can be used to explain some of trends in measured data, because this power directly affects grid temperature and, therefore, grid thermal expansion. Throughout these tests, ion current to the screen grid was intermittently measured by biasing it about $-20 \mathrm{~V}$ relative to discharge cathode potential to repel electrons. The ion current to the accelerator grid without beam extraction was inferred from tests with $40 \mathrm{~cm}$ ion optics that had a similar ion optics geometry. During those tests, the accelerator grid was biased about $-20 \mathrm{~V}$ relative to discharge cathode potential to measure the ion current, which was found to be $46 \%$ of the screen grid ion current without beam extraction. With beam extraction, the accelerator current was the total ion current collected by the grid. Grid voltages were monitored throughout the test with and without beam extraction. The ion temperature was assumed to be the discharge chamber temperature, measured in ref. 15 . The discharge plasma potential was assumed to be at anode potential for calculations of fall voltages and the accelerator grid fall voltage with beam extraction was assumed to be accelerator voltage. These data and the resulting power deposited to each grid from the plasma are listed in table 2.

According to the power deposition results in table 2, the change in screen and accelerator grid dome heights with and without beam extraction was due to discharge plasma power deposition to the grids. The power deposited to the screen and accelerator grids by the discharge plasma decreased by about $70 \%$ and $>90 \%$, respectively, when beam extraction was initiated. This was largely due to a decreased ion current to the grids when accelerator and beam power supply voltages were applied, which focused most of the discharge plasma ions away from the grids. The grid temperatures, therefore, decreased, thereby reducing the grids' thermal expansion.

The power deposition data at full power without beam extraction in table 2 also show that the power deposited to the screen grid decreased by about $10 \%$ when the main plenum flow rate was increased. This was largely due to the decreased discharge voltage, which decreased the fall voltage to the grids. This caused the screen grid's temperature to decrease, which reduced its thermal expansion and, therefore, dome height.

Using the above analysis to explain the hot grid gap behavior requires detailed thermal and mechanical analyses because the difference in dome heights is at issue. These more sophisticated analyses are beyond the scope of this work.

\section{B. Possible Resolutions for Operation With Titanium Grids}

During the thruster startup test in ref. 4, a thruster using titanium ion optics was started from room temperature and operated with beam extraction at full power within 1 minute of discharge ignition. The screen grid came into contact with the accelerator grid and, during one of the several recycles that resulted from this contact, enough energy was provided to this region of contact for the grids to bond together. An objective of the measurements reported herein was to determine operating methods to preclude this grid bonding from occurring.

A simple method of avoiding grid bonding during thruster startup is to operate the thruster initially without beam extraction and then, after the ion optics' grid gap increases, to initiate beam extraction. This was done on all of the tests reported in this study. The grid gaps shown in figs. 7 and 9 show that operating the thruster for about 10 minutes without beam extraction would be a sufficient duration to allow the grid gap to first decrease to its minimum value, and then increase to about $60 \%$ of the cold gap. The xenon propellant wasted during thruster operation without beam extraction can be minimized by reducing the main plenum flow.

Another possible method for avoiding grid bonding during thruster startup is to apply high voltage to the grids prior to igniting the discharge. The results from these tests showed that plasma power deposition to the grids is lower with beam extraction than without. Igniting the discharge with the high voltage already applied reduces power deposition to the grids and, therefore, overall grid thermal expansion. Further testing would be required to confirm this approach.

Although grid gap measurements made when transitioning from low to full power without beam extraction showed a considerable grid gap decrease, no measurements were made with beam extraction. Further testing with beam extraction will be required to determine if this transition is an issue. 


\section{Conclusions}

A simple technique for measuring the hot grid gap of an ion engine's ion optics operating with beam extraction was demonstrated. The hot grid gap at the center of the ion optics assembly was measured with a long distance microscope coupled to a digital imaging system. The microscope was focused onto an alumina pin that protruded through the center accelerator grid aperture and was mechanically attached to the screen grid. The change in hot grid gap was determined by measuring the change in pin height relative to the downstream accelerator grid surface. The use of an insulator material for the pin allowed for ion engine operation with beam extraction.

This measurement technique was successfully applied to a $30 \mathrm{~cm}$ titanium ion optics assembly mounted onto a NSTAR engineering model ion engine to help resolve startup issues associated with titanium ion optics. The cold grid gap was set to $0.69 \mathrm{~mm}$ at the ion optics' center. The required lighting increased the grid gap by about $0.035 \mathrm{~mm}$ within 25 minutes of application of the lighting, which represents about $5 \%$ of the cold grid gap. Although this effect was small, future tests can significantly reduce this effect by utilizing lighting that is better directed onto the pin rather than the entire thruster. Electrostatic pressure had no effect on the grid gap.

The grid gap and grid movement during startup from room temperature exhibited very similar behavior for both full and low power cases. Immediately following discharge ignition without beam extraction, the grids rapidly expanded. In both cases, the screen grid expanded more rapidly than the accelerator grid, likely because it had a significantly lower thermal mass, it was better exposed to the discharge plasma, and power deposition to this grid was larger. For the full and low power cases, the smallest grid gaps were achieved within about $25 \mathrm{~s}$ and about $110 \mathrm{~s}$, respectively. When beam extraction was initiated, the hot grid gaps decreased significantly and over a short duration. At full power, the hot grid gap decreased within about 2.7 minutes to a new steady-state hot grid gap of $0.34 \mathrm{~mm}$ while at low power, the hot grid gap decreased to $0.40 \mathrm{~mm}$ within about 8.7 minutes. These hot grid gap decreases occurred because the screen and accelerator grid dome heights decreased dramatically over approximately the same time period, but the accelerator gird dome height decreased more than that of the screen grid.

A significant finding from this investigation was that the hot grid gaps with and without beam extraction are significantly different. Therefore, beam extraction is required for a proper measurement of the hot grid gap during thruster operation. Another important finding was that the hot grid gaps at the ion optics' center were both significantly smaller than the cold grid gap and different at the two power levels examined. At full power, the hot grid gap at the ion optics' center was about half that of the cold grid gap. This information is important when assessing ion optics performance parameters and service life.

A simple method of avoiding grid bonding during thruster startup with $30 \mathrm{~cm}$ titanium ion optics is to operate the thruster initially without beam extraction and then, after the ion optics' grid gap increases, to initiate beam extraction. Data show that operating the thruster for about 10 minutes without beam extraction would be a sufficient duration to allow the grid gap to first decrease to its minimum value, and then increase to about $60 \%$ of the cold gap. Xenon propellant wasted during thruster operation without beam extraction can be minimized by reducing the main plenum flow. A possible method for avoiding grid bonding during thruster startup is to apply high voltage to the grids prior to igniting the discharge. Power deposition to the grids is lower with beam extraction than without. Igniting the discharge with the high voltage already applied reduces power deposition to the grids and, therefore, overall grid thermal expansion. Further testing would be required to confirm this approach.

\section{References}

${ }^{1}$ Polk, J.E., et al., "In-Flight Performance of the NSTAR Ion Propulsion System on the Deep Space One Mission," IEEE Aerospace Conference Paper 8.0304, March 2000.

${ }^{2}$ Dunning, J.W. and Benson, S.W., "NASA's Electric Propulsion Program," AIAA Paper 2002-3557, July 2002.

${ }^{3}$ Soulas, G.C., "Performance Evaluation of Titanium Ion Optics for the NASA $30 \mathrm{~cm}$ Ion Thruster," IEPC Paper 01-92, October 2001.

${ }^{4}$ Soulas, G.C., "Performance of Titanium Optics on a NASA $30 \mathrm{~cm}$ Ion Thruster," AIAA Paper 2000-3814, July 2000.

${ }^{5}$ Soulas, G.C., Haag, T.W., Patterson, M.J., and Rawlin, V.K., "Titanium Optics for Ion Thrusters," IEPC Paper 99-149, October 1999.

${ }^{6}$ Ramsey, W.D., "12-cm Multi-cusp Ion Thruster Inert Gas Performance," NASA Contractor Report CR-168208, Loral EOS Document 84-07-29, July 1984. 
${ }^{7}$ MacRae, G.S., Zavesky, R.J., and Gooder, S.T., "Structural and Thermal Response of $30 \mathrm{~cm}$ Diameter Ion Thruster optics," AIAA Paper 89-2719, July 1989.

${ }^{8}$ Pollard, J.E. and Welle, R.P., "Thrust Vector Measurements with the T5 Ion Engine," AIAA Paper 95-2829, July 1995.

${ }^{9}$ Christensen, J.A., et al., "Design and Fabrication of a Flight Model $2.3 \mathrm{~kW}$ Ion Thruster for the Deep Space 1 Mission," AIAA Paper 98-3327, July 1998.

${ }^{10}$ Sovey, J.S., et al., "Development of an Ion Thruster and Power Processor for New Millenium's Deep Space 1 Mission," AIAA Paper 97-2778, December 1997.

${ }^{11}$ Rawlin, V.K., et al., "An Ion Propulsion System for NASA's Deep Space Missions," AIAA Paper 4612, September 1999.

${ }^{12}$ Soulas, G.C., Domonkos, M.T., and Patterson, M.J., "Performance Evaluation of the NEXT Ion Engine," AIAA Paper 2003-5278, July 2003.

${ }^{13}$ Pinero, L.R., Patterson, M.J., and Satterwhite, V.E., "Power Console Development for NASA's Electric Propulsion Outreach Program," IEPC Paper 93-250, September 1993.

${ }^{14}$ Van Noord, J.L., "Thermal Modeling of an Ion Thruster," NASA Contractor Report CR-2000-209792, February 2000.

${ }^{15}$ Rawlin, V.K., Patterson, M.J., and Becker, R., "Thermal Environment Testing of NSTAR Engineering Model Ion Thrusters," IEPCPaper 97-051, August 1997. 
Table 1. Nominal thruster operating parameters. ${ }^{\text {a }}$

\begin{tabular}{ccccccccc}
\hline $\begin{array}{c}\text { Power } \\
\text { Level }\end{array}$ & $\begin{array}{c}\text { Power } \\
\text { Level } \\
\text { Designation }\end{array}$ & $\begin{array}{c}\text { Input } \\
\text { Power, } \\
\mathrm{kW}\end{array}$ & $\begin{array}{c}\text { Nominal } \\
\text { Beam } \\
\text { Current, } \\
\mathrm{A}, \mathrm{b}\end{array}$ & $\begin{array}{c}\text { Actual } \\
\text { Beam } \\
\text { Current, } \\
\mathrm{A}\end{array}$ & $\begin{array}{c}\text { Beam } \\
\text { Voltage, } \\
\mathrm{V}\end{array}$ & $\begin{array}{c}\text { Accelerator } \\
\text { Voltage, V }\end{array}$ & $\begin{array}{c}\text { Main } \\
\text { Flow, } \\
\text { sccm }\end{array}$ & $\begin{array}{c}\text { Discharge } \\
\text { Cathode } \\
\text { Flow, sccm } \\
\text { sccm }\end{array}$ \\
\hline Full & TH15 & 2.3 & 1.76 & 1.83 & 1100 & -180 & 23.4 & 3.70 \\
Low & TH0 & 0.5 & 0.51 & 0.50 & 650 & -150 & 5.98 & 2.47 \\
\hline
\end{tabular}

${ }^{a}$ Nominal NSTAR operating condition for discharge chamber and ion optics.

${ }^{\mathrm{b}}$ Power supply current or voltage.

Table 2. Power deposition parameters and values for low and full power with and without beam extraction.

\begin{tabular}{|c|c|c|c|c|c|c|c|}
\hline \multirow{2}{*}{$\begin{array}{l}\text { Power } \\
\text { Level }\end{array}$} & \multirow{2}{*}{$\begin{array}{c}\text { Beam } \\
\text { Extraction? }\end{array}$} & \multicolumn{3}{|c|}{ Screen Grid Power Deposition } & \multicolumn{3}{|c|}{ Accelerator Grid Power Deposition } \\
\hline & & $\begin{array}{c}\text { Ion } \\
\text { Current, } \\
\text { A }\end{array}$ & $\begin{array}{c}\text { Fall } \\
\text { Voltage, }{ }^{\mathrm{a}} \\
\mathrm{V}\end{array}$ & $\begin{array}{c}\text { Power, } \\
\text { W }\end{array}$ & $\begin{array}{c}\text { Ion } \\
\text { Current, } \mathrm{A}\end{array}$ & $\begin{array}{c}\text { Fall } \\
\text { Voltage, }{ }^{\mathrm{a}} \\
\text { V }\end{array}$ & $\begin{array}{c}\text { Power, } \\
\text { W }\end{array}$ \\
\hline \multirow[t]{3}{*}{ Full $^{b}$} & $\mathrm{No}^{\mathrm{d}}$ & 1.43 & 25.3 & 47.1 & $0.66^{\mathrm{e}}$ & 26.1 & 22.1 \\
\hline & No & 1.47 & 21.5 & 42.9 & $0.68^{\mathrm{e}}$ & 19.7 & 18.4 \\
\hline & Yes & 0.42 & 25.8 & 14.0 & 8.3 & 180 & 1.6 \\
\hline \multirow[t]{2}{*}{ Low $^{c}$} & $\mathrm{No}^{\mathrm{d}}$ & 0.31 & 27.8 & 12.0 & $0.17^{\mathrm{e}}$ & 28.4 & 5.6 \\
\hline & Yes & 0.11 & 28.0 & 3.9 & 1.4 & 150 & 0.2 \\
\hline
\end{tabular}

${ }^{\mathrm{a}}$ Discharge plasma potential assumed to be at anode potential; accelerator grid fall voltage with beam extraction assumed to be accelerator voltage.

${ }^{\mathrm{b}}$ Ion temperature assumed to be $290^{\circ} \mathrm{C}$ from discharge temperature measurements of ref. 15 .

${ }^{\mathrm{c}}$ Ion temperature assumed to be $190{ }^{\circ} \mathrm{C}$ from discharge temperature measurements of ref. 15 .

${ }^{\mathrm{d}}$ Main plenum flow reduced to increase discharge voltage.

${ }^{\mathrm{e}}$ Inferred from $40 \mathrm{~cm}$ ion optics test data.

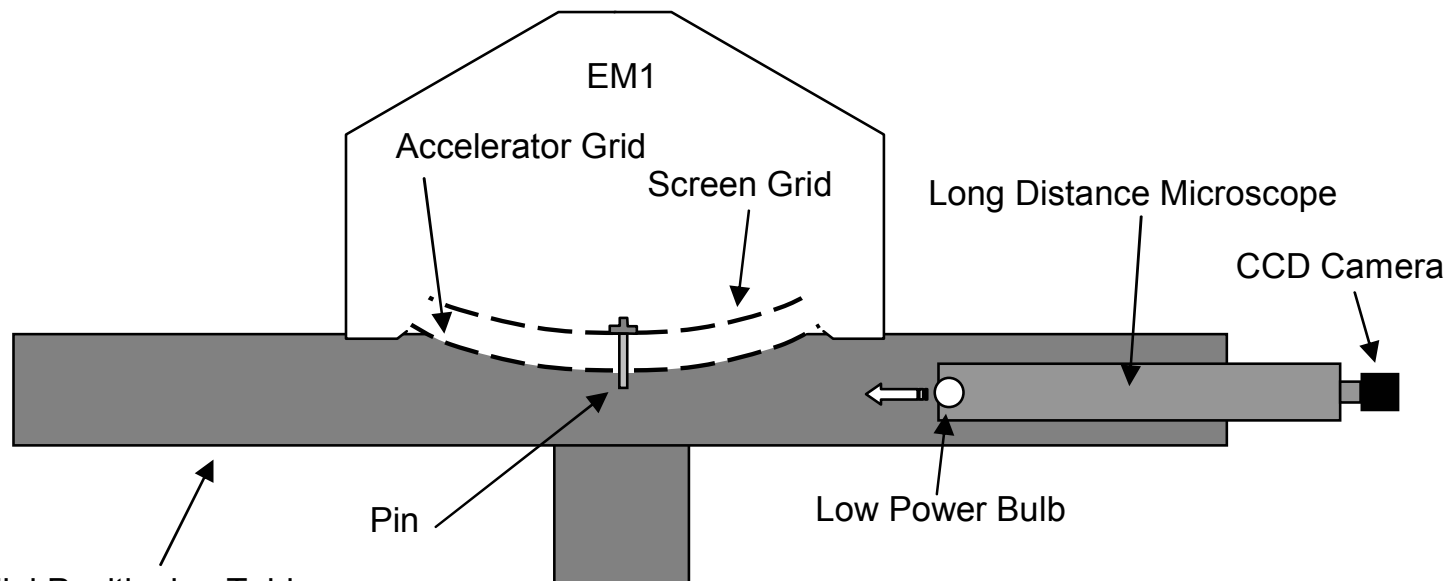

Radial Positioning Table
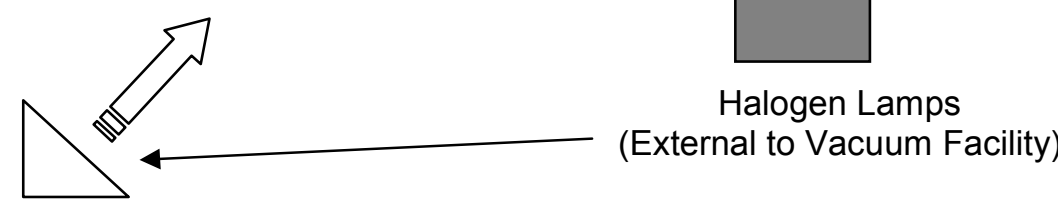

Axial Positioning Table

Figure 1. Schematic of hot grid gap measurement setup. 


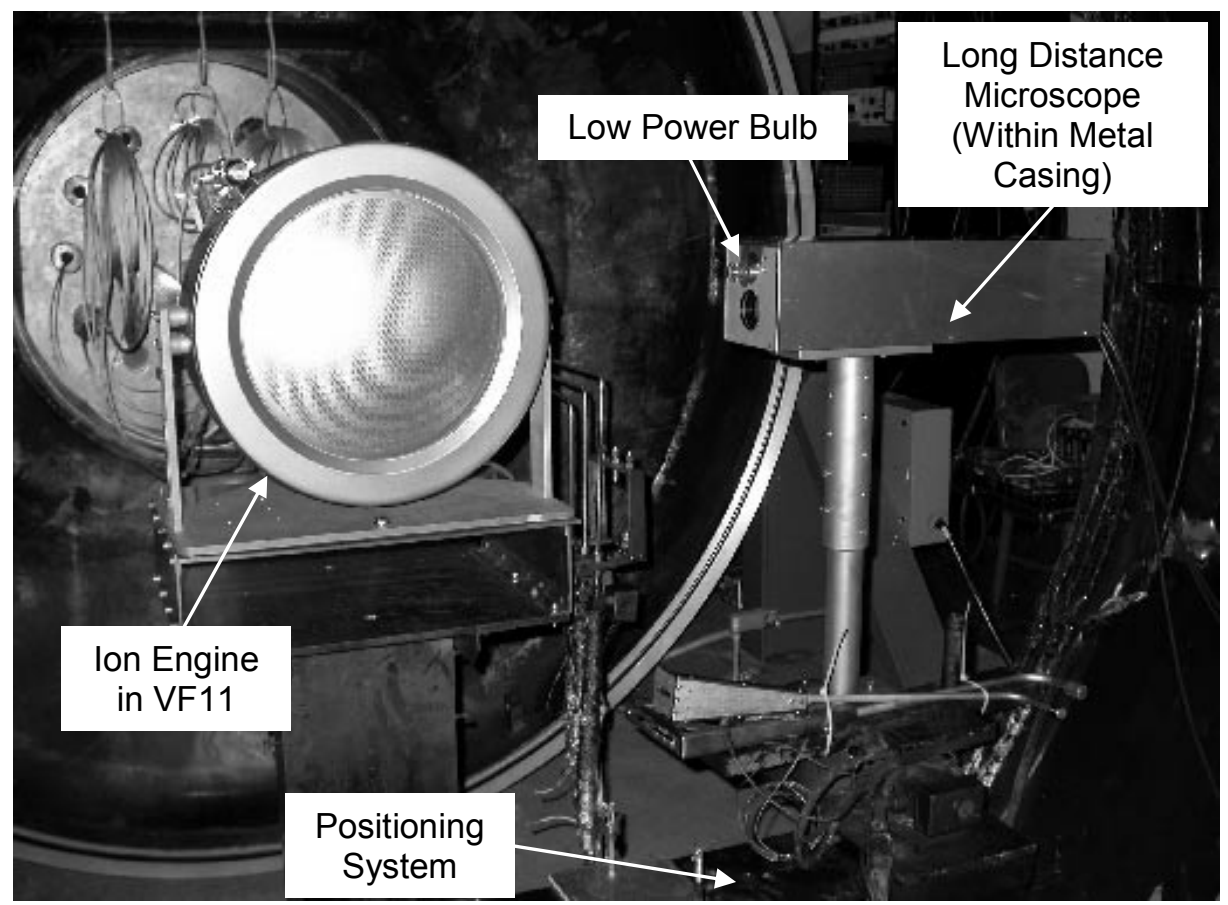

Figure 2. Photograph of pretest setup (pin not visible and halogen lamps not shown).

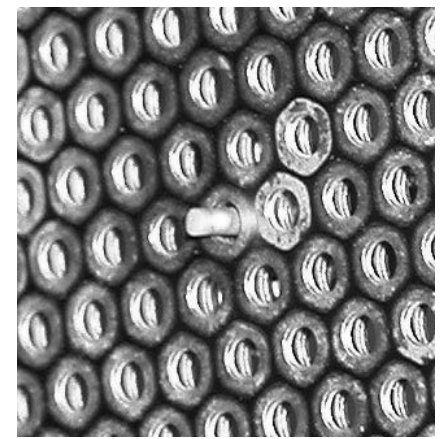

a. Downstream pin.

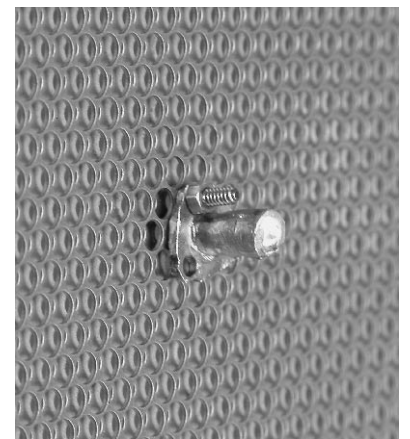

b. Upstream pin mount.

Figure 3. Pretest downstream and upstream photographs of pin mounted to the titanium ion optics.

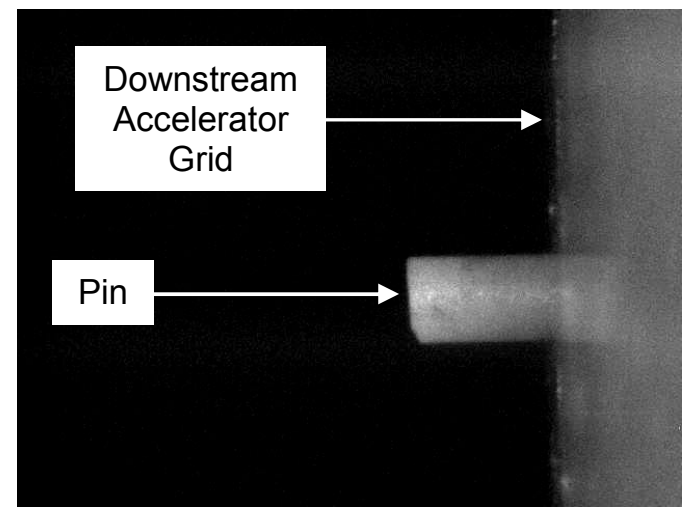

Figure 4. Image of pin and downstream accelerator grid from the long distance microscope. 


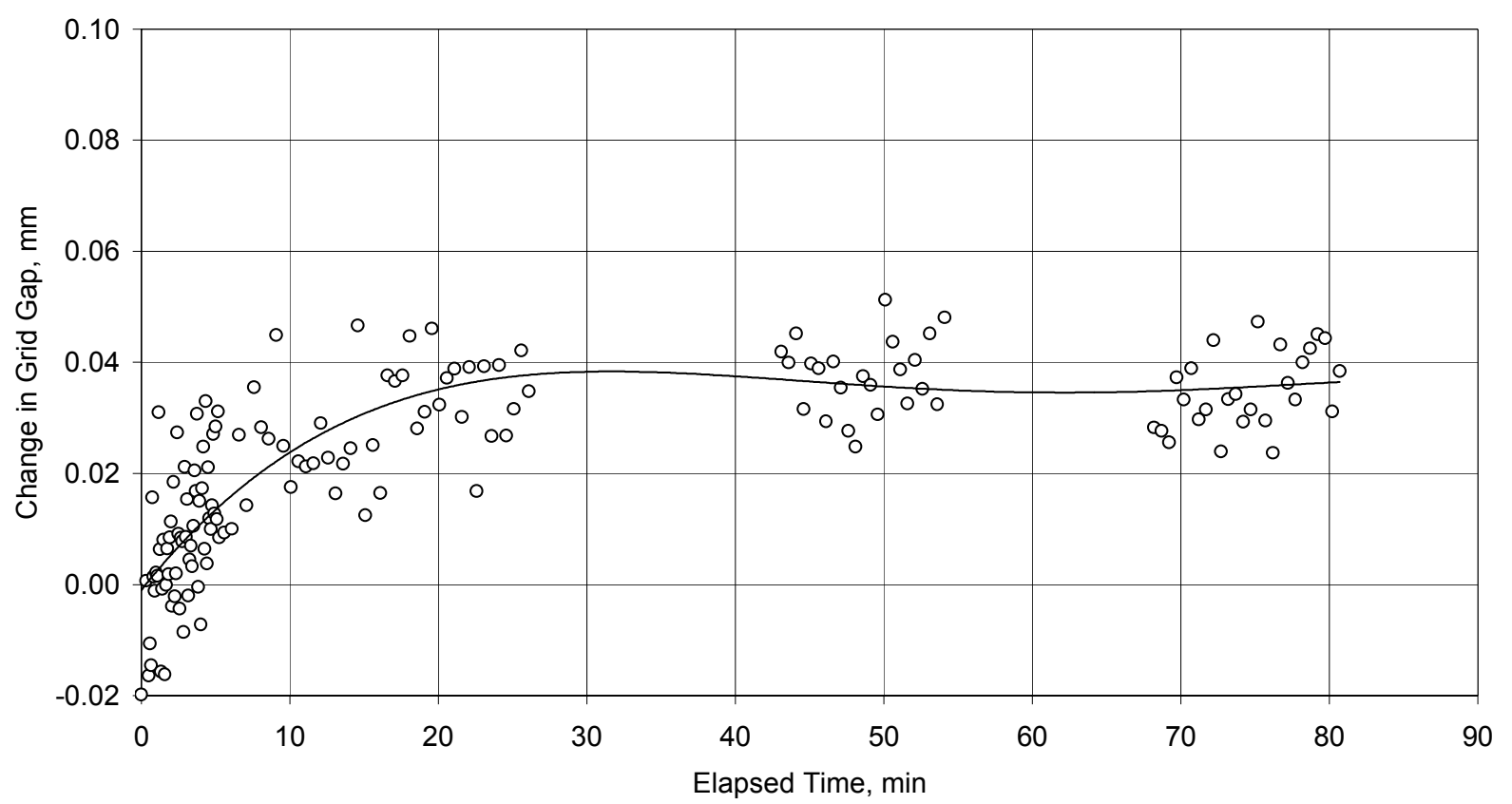

Figure 5. Change in grid gap as a function of elapsed time due to heating from the required lighting.

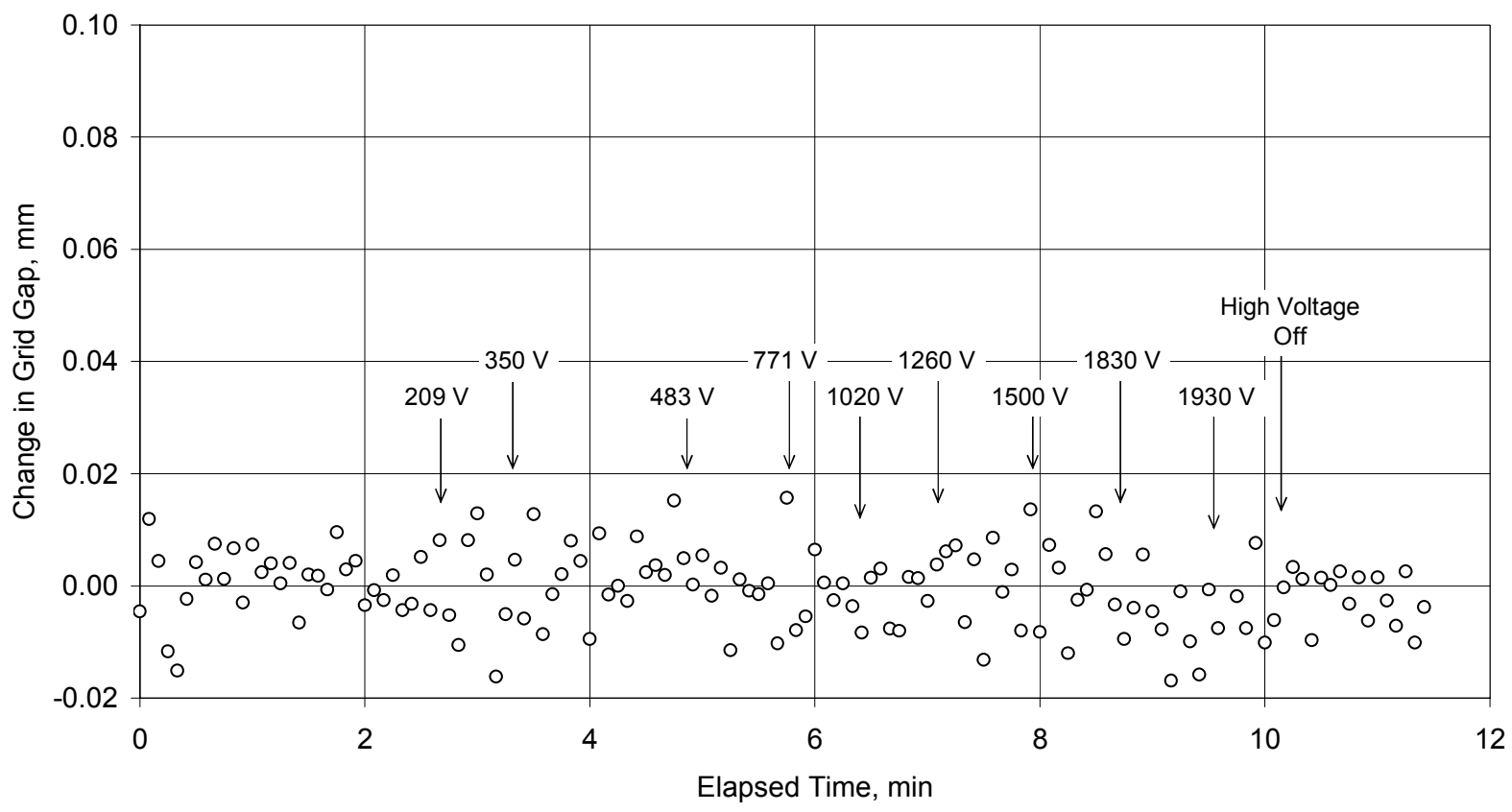

Figure 6. Change in grid gap as a function of elapsed time due to electrostatic forces. 


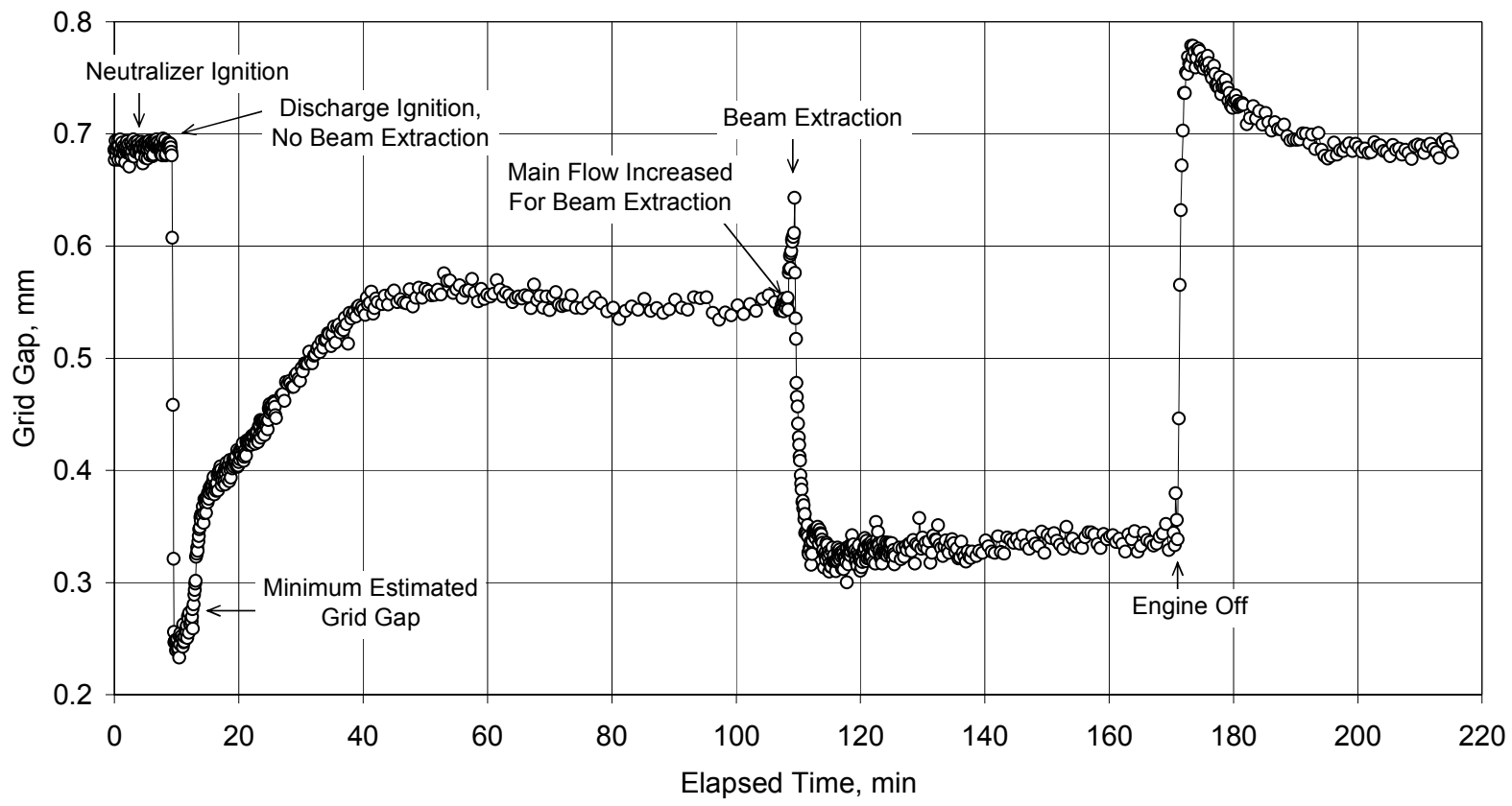

Figure 7. Grid gap as a function of elapsed time at full power without and with beam extraction.

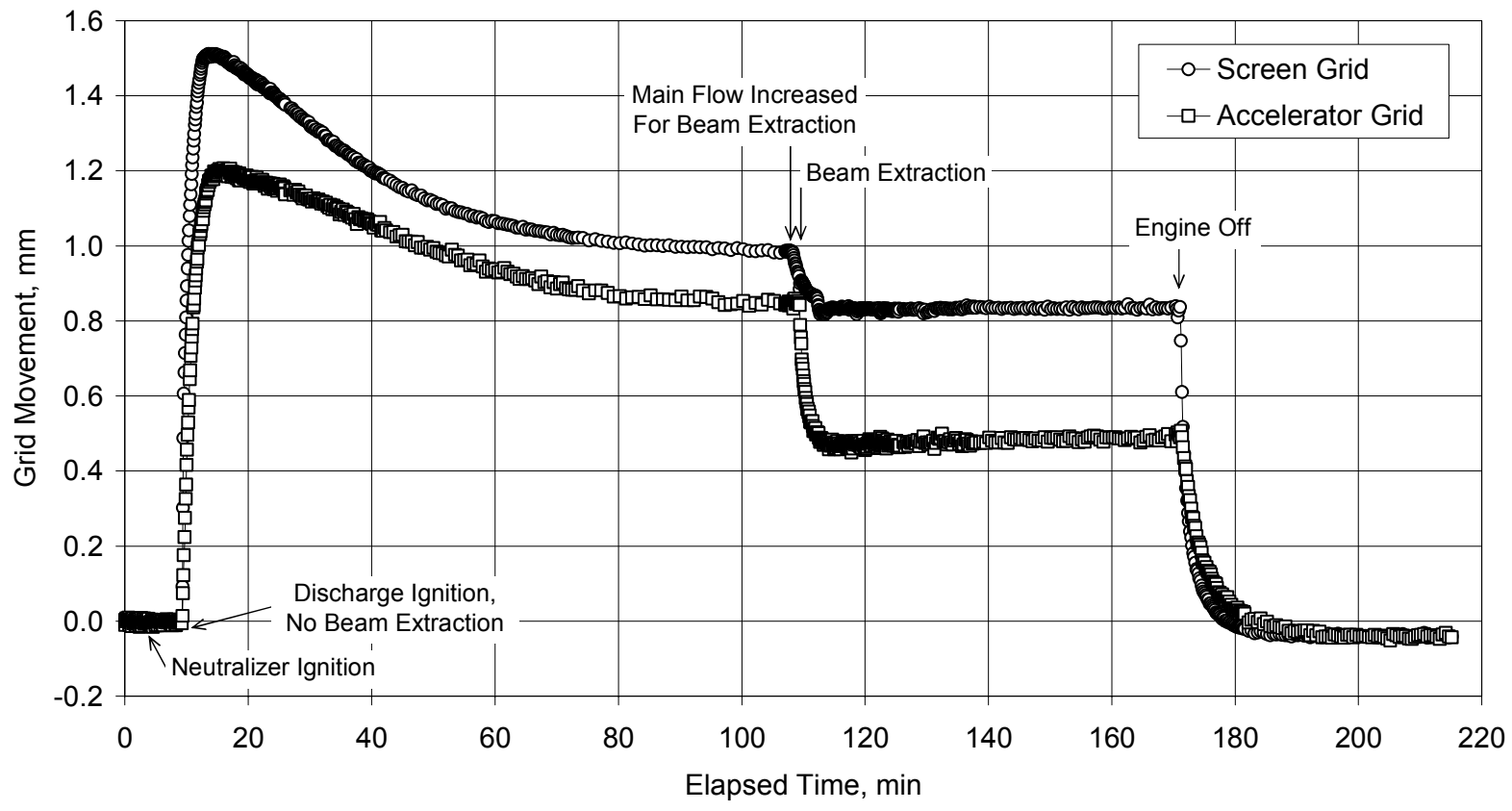

Figure 8. Grid movement as a function of elapsed time at full power without and with beam extraction. 


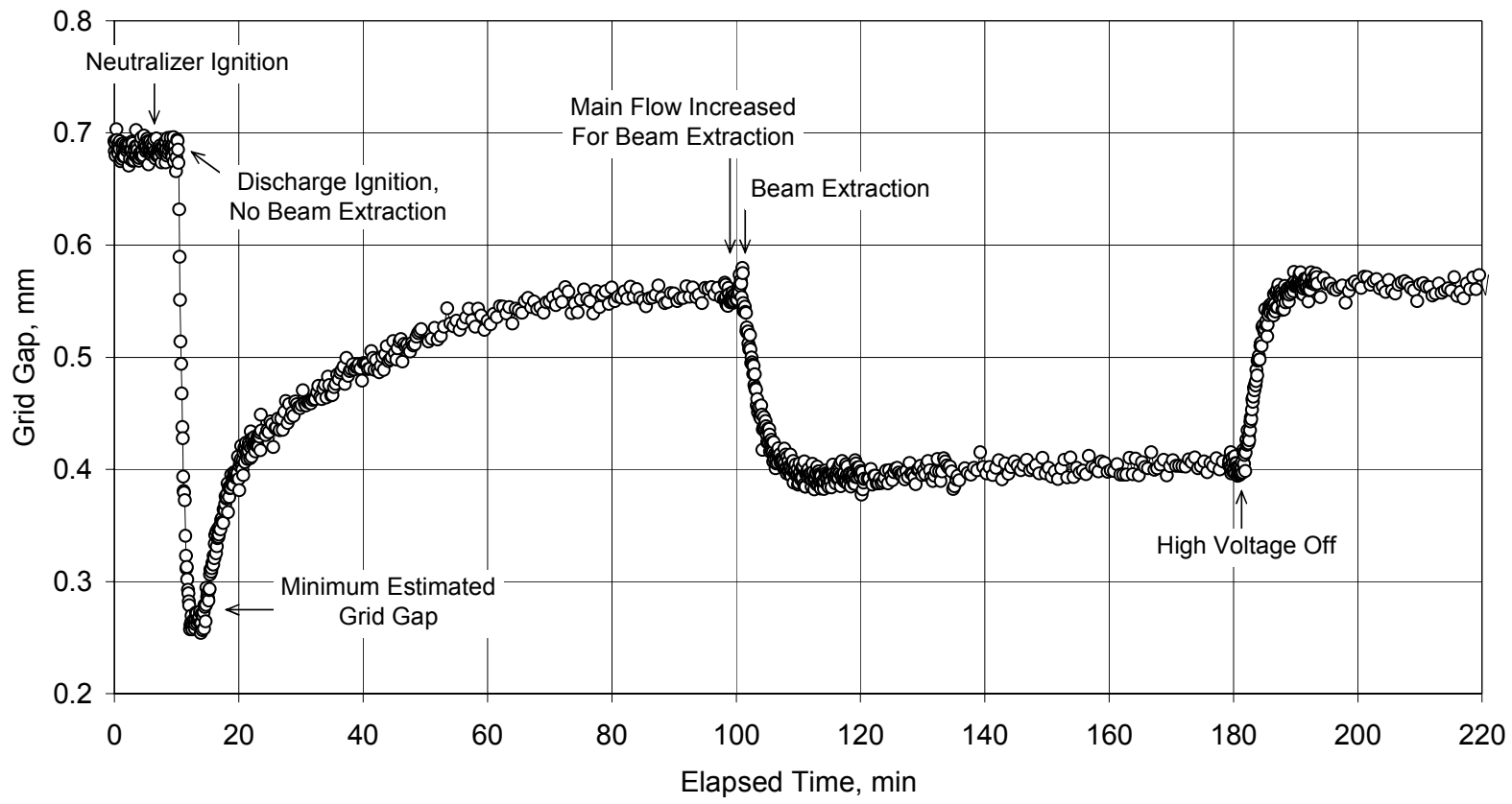

Figure 9. Grid gap as a function of elapsed time at low power without and with beam extraction.

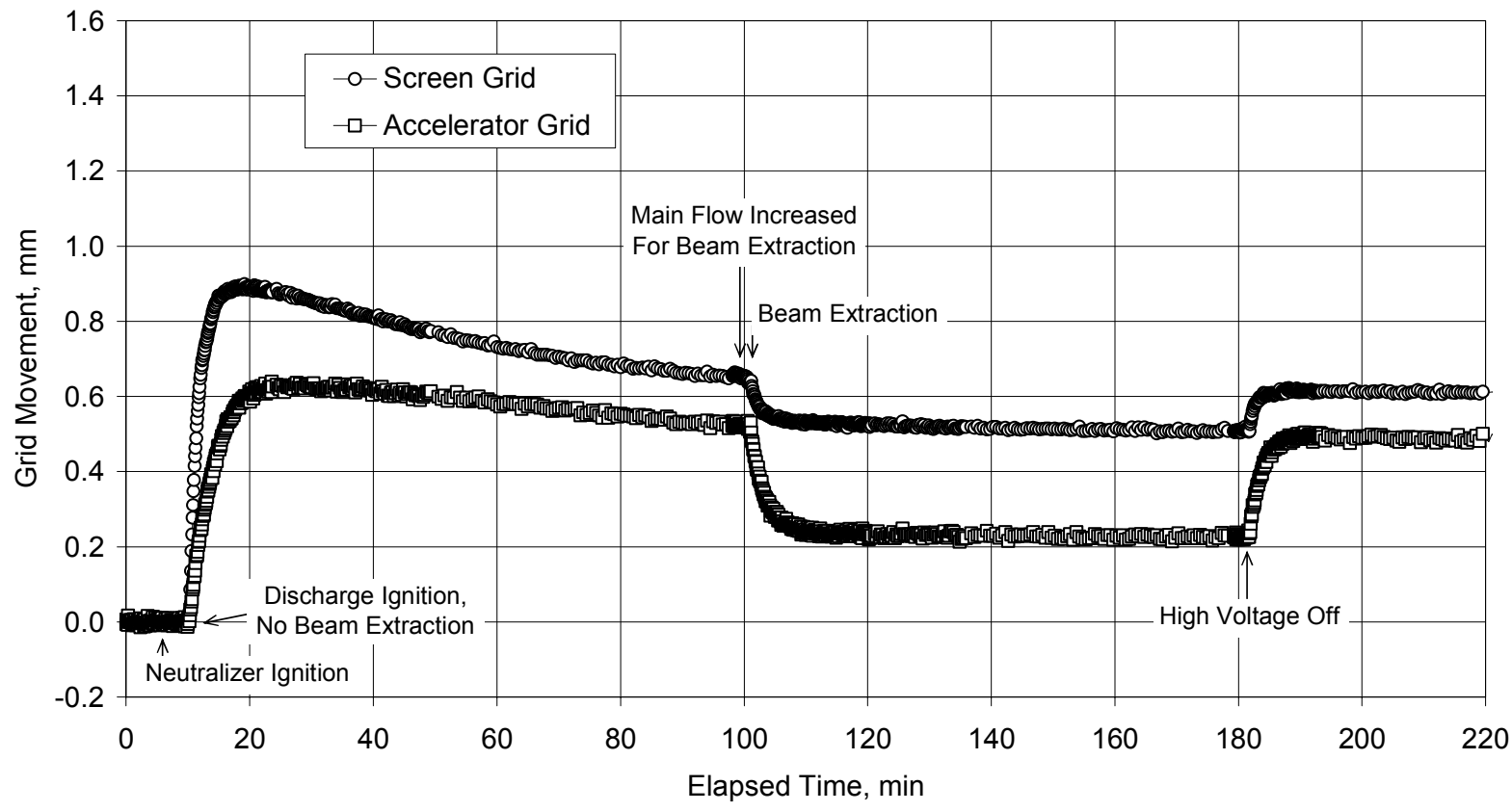

Figure 10. Grid movement as a function of elapsed time at low power without and with beam extraction. 


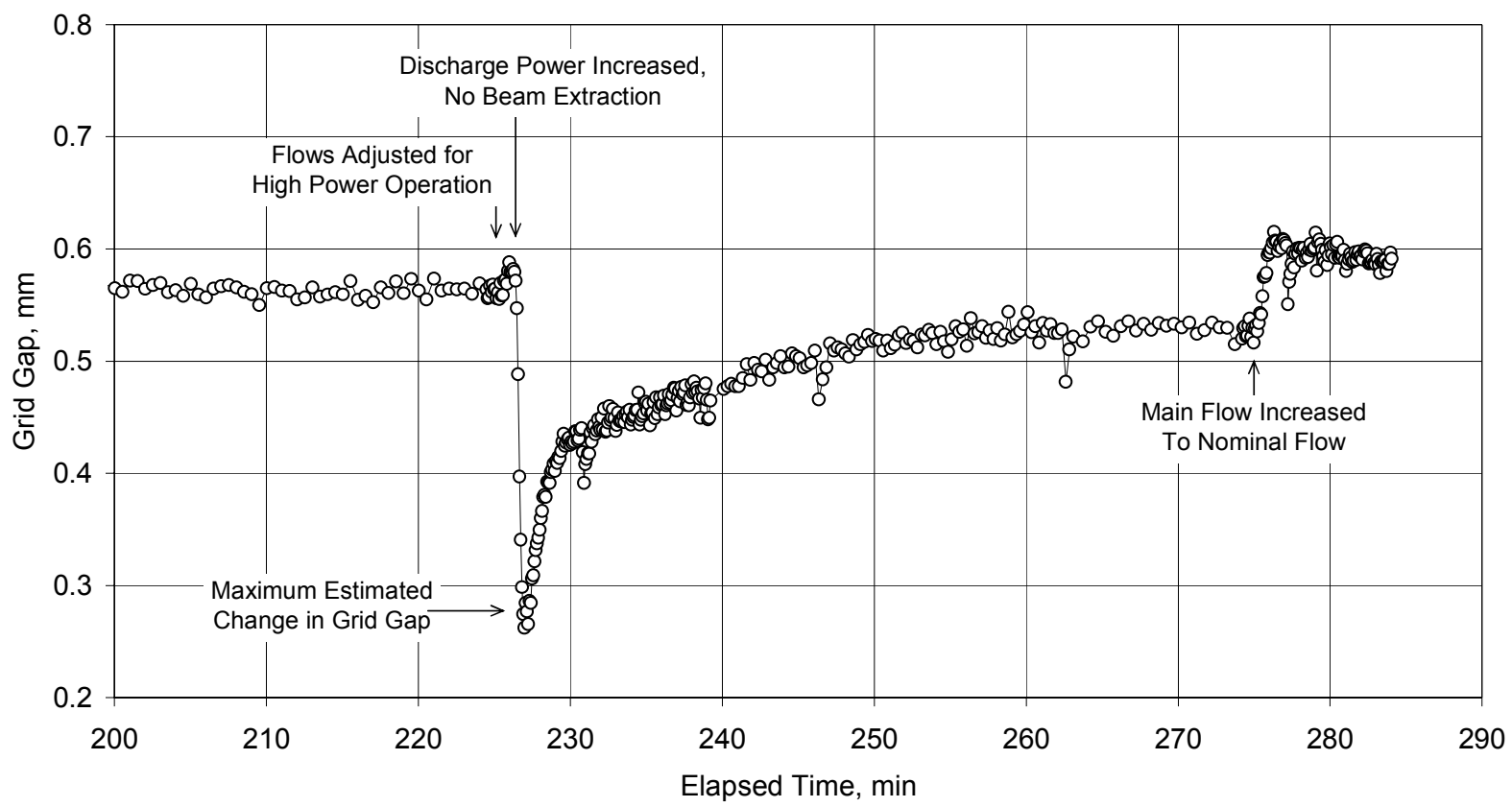

Figure 11. Grid gap as a function of elapsed time while transitioning from low to full power without beam extraction.

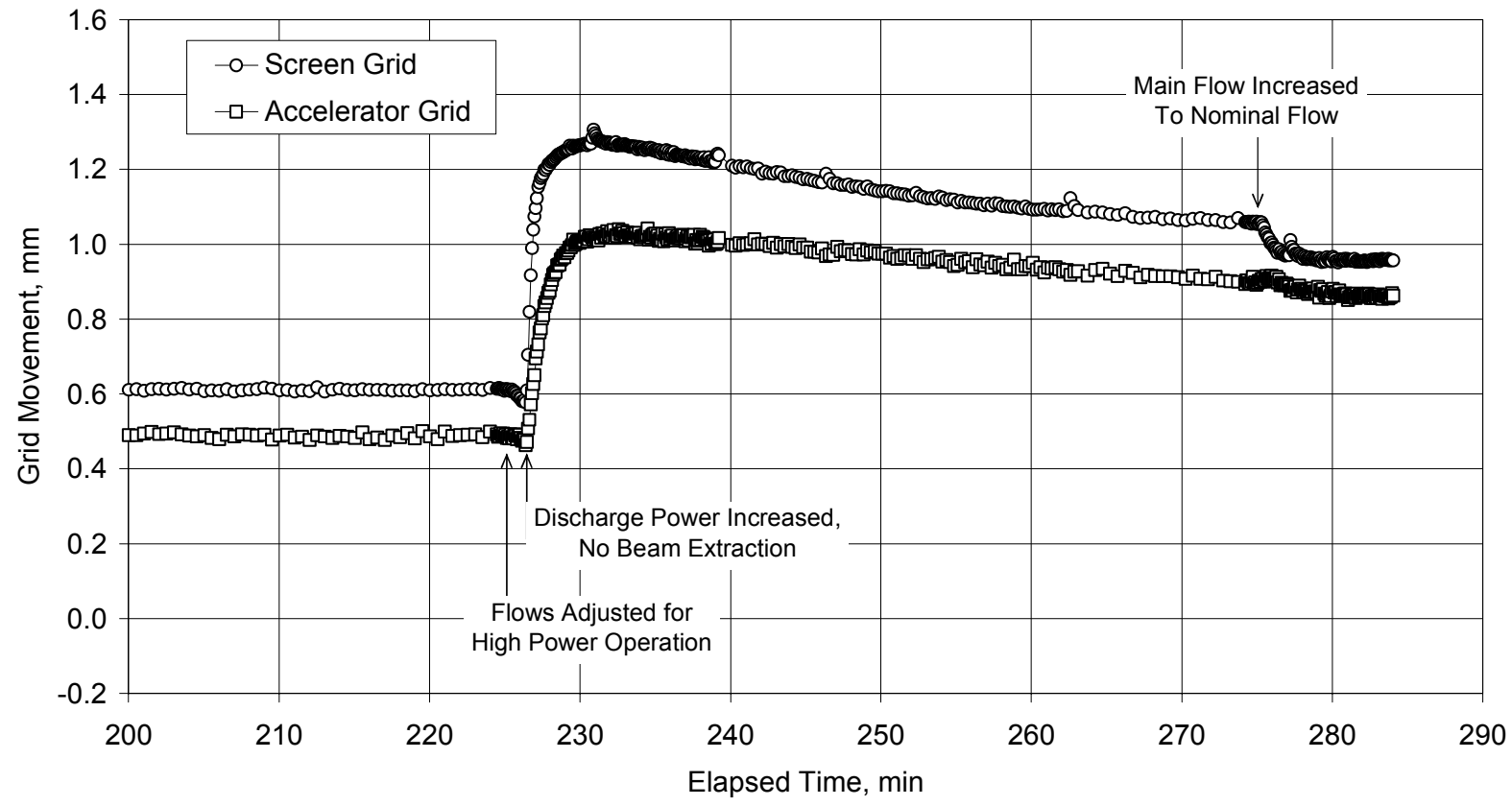

Figure 12. Grid movement as a function of elapsed time while transitioning from low to full power without beam extraction. 
Public reporting burden for this collection of information is estimated to average 1 hour per response, including the time for reviewing instructions, searching existing data sources, gathering and maintaining the data needed, and completing and reviewing the collection of information. Send comments regarding this burden estimate or any other aspect of this collection of information, including suggestions for reducing this burden, to Washington Headquarters Services, Directorate for Information Operations and Reports, 1215 Jefferson Davis Highway, Suite 1204, Arlington, VA 22202-4302, and to the Office of Management and Budget, Paperwork Reduction Project (0704-0188), Washington, DC 20503.

\begin{tabular}{|l|l|l}
\hline 1. AGENCY USE ONLY (Leave blank) & $\begin{array}{c}\text { 2. REPORT DATE } \\
\text { August } 2004\end{array}$ & $\begin{array}{r}\text { 3. REPORT TYPE AND DATES COVERED } \\
\text { Technical Memorandum }\end{array}$
\end{tabular}

\section{TITLE AND SUBTITLE}

Ion Engine Grid Gap Measurements

6. AUTHOR(S)

George C. Soulas and Michael M. Frandina

\section{FUNDING NUMBERS}

WBS-22-755-70-04

8. PERFORMING ORGANIZATION REPORT NUMBER

E-14723

John H. Glenn Research Center at Lewis Field

Cleveland, Ohio 44135-3191

10. SPONSORING/MONITORING AGENCY REPORT NUMBER

National Aeronautics and Space Administration

Washington, DC 20546-0001

NASA TM-2004-213215

AIAA-2004-3961

\section{SUPPLEMENTARY NOTES}

Prepared for the 40th Joint Propulsion Conference and Exhibit cosponsored by AIAA, ASME, SAE, and ASEE, Fort Lauderdale, Florida, July 11-14, 2004. George C. Soulas, NASA Glenn Research Center; and Michael M. Frandina, QSS Group, Inc., 21000 Brookpark Road, Cleveland, Ohio 44135. Responsible person, George C. Soulas, organization code 5430, 216-977-7419.

12a. DISTRIBUTION/AVAILABILITY STATEMENT 12b. DISTRIBUTION CODE

Unclassified - Unlimited

Subject Category: 20

Distribution: Nonstandard

Available electronically at http://gltrs.grc.nasa.gov

This publication is available from the NASA Center for AeroSpace Information, 301-621-0390.

\section{ABSTRACT (Maximum 200 words)}

A simple technique for measuring the grid gap of an ion engine's ion optics during startup and steady-state operation was demonstrated with beam extraction. The grid gap at the center of the ion optics assembly was measured with a long distance microscope that was focused onto an alumina pin that protruded through the center accelerator grid aperture and was mechanically attached to the screen grid. This measurement technique was successfully applied to a $30 \mathrm{~cm}$ titanium ion optics assembly mounted onto an NSTAR engineering model ion engine. The grid gap and each grid's movement during startup from room temperature to both full and low power were measured. The grid gaps with and without beam extraction were found to be significantly different. The grid gaps at the ion optics' center were both significantly smaller than the cold grid gap and different at the two power levels examined. To avoid issues associated with a small grid gap during thruster startup with titanium ion optics, a simple method was to operate the thruster initially without beam extraction to heat the ion optics. Another possible method is to apply high voltage to the grids prior to igniting the discharge because power deposition to the grids from the plasma is lower with beam extraction than without. Further testing would be required to confirm this approach.

\section{SUBJECT TERMS}

Ion thruster; Ion engine; Ion propulsion; Ion optics; Grid gap

17. SECURITY CLASSIFICATION OF REPORT

Unclassified
18. SECURITY CLASSIFICATION OF THIS PAGE

Unclassified
19. SECURITY CLASSIFICATION OF ABSTRACT

Unclassified
15. NUMBER OF PAGES

20

16. PRICE CODE

\section{LIMITATION OF ABSTRACT}



